\title{
The Textilesphere: The threshold of everyday contacts
}

\author{
Yeseung Lee
}

De Montfort University

* The Version of Record of this manuscript has been published by Taylor \& Francis and is available in Textile: Cloth and Culture (5 September 2019).

https://www.tandfonline.com/eprint/GP4UCRMB2R2XB9BDMZMD/full?target=10.1080/1475 $\underline{9756.2019 .1652429}$

\begin{abstract}
A sense of displacement pervades contemporary life, with the global crisis of forced migrations, increasingly modular and distributed families, and remote social interactions replacing familiar ways of being in a space with others. This sentiment, together with the widening application of highly advanced textiles in many areas of the built environment, calls for an appraisal of textiles in relation to notions of home and belonging. Drawing on a range of academic and practitioner literature, brought together under 'relational approaches', this essay puts forward the 'textile-sphere' as a new ontological category and a critical device for textiles thinking within this context of societal and technological changes. The textile-sphere is an affective spatiality generated by physical wear as indexical traces of everyday life, emphasizing sustained physical contact as an essential of home. It suggests a new way of thinking about textiles which transcends 2D-3D, human-nonhuman or material-immaterial dichotomies, focusing, instead, on the flexible relations between surfaces. The textile-sphere is a useful tool for exploring the complexity of the contemporary spatiality in relation to various physical and virtual surfaces, and the role textiles can play in interrogating this complexity, letting us contemplate what it means to be 'in touch', to be home.
\end{abstract}

Keywords: touch, wear, index, relation, home, material, affect

\section{Textiles, home and displacement}

The issue of uninhabitable space has become weighty in our consciousness again. Instances of mass migration or the loss of home that ensue from natural and humanmade disasters lead us to reflect on what it is like to be displaced. What does "home" consist of today? What do we consider to be the material or immaterial qualities of home $?^{1}$ The fact that textiles feature prominently in various forms of ephemeral 
architecture - the type of "home" only intended for passing through or temporary inhabitation-leads me to explore contemporary notions of space, home and belonging through textiles. Contemporary textiles bear yet another kind of loss-less troubling but no less significant - that is, the loss of touch and of the inter- and multi-sensorial experiences that touch allows. Various virtual surfaces encountered in educational, entertainment or commercial contexts play increasingly important roles in everyday lives, replacing familiar or conventional ways of feeling or making an object, and of being in a space with others. Such changes defamiliarize textiles, prompting the questions: what then do "ordinary" textiles do? Why do we feel at home with textiles? The aim of this essay is to explore the questions raised above and suggest new ways of thinking about textiles and the spatiality they afford, in keeping with changing conditions of being and living.

The essay begins by examining the background behind why a renewed approach to textiles thinking might be necessary. It then elaborates on the position taken as a means to explore the questions raised above, by briefly outlining some of the main characteristics of "relational approaches" in arts, humanities and social science scholarship. This subsequently allows me to put forward, in the second section, the "textile-sphere" as a new ontological category and a device for textiles thinking within the societal, material and technological changes touched upon above. The textile-sphere is enabled by physical marks as an index of absence, making typically disparate categories - here-there, now-then, material-immaterial, surface-volume, humannonhuman - radically continuous. It highlights textiles as an essentially relational material and suggests that physical proximity or contact is paramount in generating affective spatiality, that is, the sense of home or of belonging. Next, I consider psychoanalyst Didier Anzieu's theory of the "skin ego" and Peter Sloterdijk's philosophy of spheres ("spherology") in relation to the textile-sphere. Although humancentred, they both compellingly expound on the spatiality of primary relationships between a baby and its mothering person $(s)^{2}$ and the profound role they continue to play in later social spaces. I suggest that textiles are the material of home and of other intimate social spheres, the material which generates the sense of being together in a space. The final section presents a few examples of artistic interventions that effectively explicate the textile-sphere by foregrounding the sense of loss though indexical traces of touch. Considering the increasingly central roles textiles play in the twenty-first-century built environment, as well as in our psychological well-being, a new textile thinking 
must transcend any 2D-3D, human-nonhuman or material-immaterial dichotomies, and focus, instead, on the process of relating and relations between surfaces.

\section{The background and Relational Approaches}

In the documentary film Human Flow (2017), artist Ai Weiwei follows, in Kenya, Malaysia, Israel, Jordan, North America and many ports of Europe, the plight of migrants on the move, attempting to visualize the immensity of the global crisis. So many people have left their familiar milieux, bundling themselves up in cloth and clothing. Textiles seem to be the essential layer and space for lives in limbo, as "homes" are lost, carried and remade with and through the material. For Syrian refugees arriving in the Greek island of Lesbos, gestures of empathy are rendered in the form of Mylar blankets. Now ubiquitous, Mylar is one of the early examples of "smart" textiles initially developed for astronauts and elite soldiers in NASA-supported cutting-edge companies in the 1960s (Küchler 2008, 113). High-performing textiles such as Mylar, Kevlar or Gore-tex modulate the relationship — protection and/or adaptation — between the human body and its (harsh) surroundings. They function as an active skin, a mediating mobile environment. This function is further enhanced in those textiles that are incorporated into "intelligent" architecture, smart fashion and other highly sensorized environments designed to be worn or inhabited. It seems the boundaries between the skin, interior, clothing and architectural surfaces are gradually collapsing into the uber-category of highly advanced textiles.

Another collapse of boundaries is happening between actual and virtual textiles: virtual clothing, commonly referred to as "skins" in games or 3D animations, has now entered the fashion industry via the world of social media, ${ }^{3}$ while many emerging designers are exploring virtual textiles, paying close attention to haptic and other sensorial properties of textiles (Harris 2013; Igoe forthcoming). It is important to note that these developments are not introducing entirely new functions, but rather emulate and enhance the existing properties of "ordinary" textiles. It is the becoming newly aware of ordinary textiles as a mediatic and mobile environment, at once physical and virtual, that is of interest here. For example, virtuality is already potent in conventional textiles, as their material qualities (soft, stretchy, absorbent, smell, sound, colour, etc.) generate immaterial qualities such as atmosphere, ambience or affect. From the moment of being swaddled, to the point of being shrouded, the cloth is the archetypal everyday 
material which wears us as we wear it, affecting our bodies, thoughts and emotions. The recent technical and social conditions discussed above defamiliarize ordinary textiles, thereby prompting us to reevaluate their familiar qualities and to reconceptualize them. The loss of tactual interaction might be compensated by better understanding of what ordinary textiles do and have always done, so that qualities precious to us are kept and enhanced in the next generation of textiles as environment.

With increased mobility and distributed existence across the globe and across the physical-virtual world, it is probable that we have different temporal, spatial or material awareness from that of earlier, pre-digital times. Anthropologist Susanne Küchler (2014) suggests that different modalities of fabrication and the way we inhabit social and material worlds may be closely linked. ${ }^{4}$ Textiles play an important role in the shift away from depth ontology towards surface ontology, as the thinking, sensing and communicating functions are distributed on the surface of "intelligent" artefacts such as clothing, walls, household objects. Therefore, recent scholarship in humanities and the social sciences has been developing "a new kind of surface ontology which replaces the opposition of inside and outside, invisible and visible, immaterial and material with a complementary relation that thrives on transformation rather than distinction." (Küchler 2008, 116) This essay (re)considers the textile as a mediatic environment - at once material and immaterial surface, space and atmosphere - and suggests the "textilesphere" as an ontological category and a critical medium for investigating the human and nonhuman link in relation to the spatiality and the sense of home.

As I will go on to explain further below, the type of spatiality this essay proposes - the category of the textile-sphere - is a place borne of physical touch, with no a priori surface or place before marking or contact takes place. It is "affective senses of space" or "territories of feeling" (Thrift 2010, 292) that emerge as textiles become integrated with everyday lives. Such textile thinking has affinities with anti-humanist, relational approaches in recent scholarship in the humanities and the social sciences. Fields of study as diverse as psychoanalysis, archelogy, sociology, education, anthropology, geography, philosophy and media studies are adopting relational approach as research framework. As thinking about textiles in terms of spatiality involves the consideration of diverse human and nonhuman elements - old and new technologies including human sensory organs; material and mediatic qualities of cloth; sound or air; modes of engagement and movement; speculations on the formation of subjects - interdisciplinary and relational approaches are essential. The increasing 
awareness of body-machine-material entanglements - as a result of works being carried out in areas such as biotechnology, robotics, cybernetics or artificial intelligence- - have destabilized and de-centred the liberal humanist subject (Joy and Dionne 2010, 3), opening up spaces for relational thinking across the social sciences and humanities. Donna Haraway's influential figure of the cyborg (1991) or her notion of "companion species" (2003), for example, subvert the long-standing Western distinctions between living and non-living, between human and animals. Haraway's cyborgs do not have identities but instead are relations and affinities. Relational approaches refuse binary viewpoints, seeing the world as fundamentally relational and processual. ${ }^{5}$ The human is a constituent ("actants") ${ }^{6}$ of a distributed system as agency — theorized variously as "networks" (actor-network theory), "meshworks" (Ingold 2008) or "assemblages" (Deleuze and Guattari 1987; Delanda 2006) — as is the nonhuman such as animals, affectivity, organic and geophysical systems, materiality or technologies (Grusin 2015, vii). ${ }^{7}$ This resonates with the spatiality of textiles suggested above, as practices of relating constitute individuals, and "society 'is relation' and does not 'have relations"'. (Pierpaolo Donati quoted in Dépelteau 2018,3) I suggest that various human and nonhuman "affectants"—with "affect" understood as an intensity moving through human and nonhuman bodies (Massumi 1995) — constitute the "system" of the textilesphere.

More generally, relational thinking also sheds light on the fact that globalization and technological advancement do not necessarily add to our comprehensive understanding of the world, and we do not see the scale of the impacts that each of our actions might have. Therefore, "there is an urgency in coming to see the world as a web of interrelated processes of which we are integral parts" (Robert Mesle quoted in Dépelteau 2018, 16). Global-scale political, social or environmental changes may be much more closely linked to our relations to other humans and nonhumans in everyday microsocial spheres than is often assumed.

\section{The Textile-sphere: a relational space}

To explore the mediatic spatiality of textiles, this section focuses on its tactual and affective materiality, emphasizing the aspect of the "lived" environment as a matrix of indexical traces. The link between textiles and space has often been explored from an architectural point of view. Architect Gottfried Semper's theory of dressing- 
Bekleidung (Semper [1860] 2004) — for example, links textiles and walls via their mutual ability to "cover" and the "spatiality implied in the act of demarcating what is inside from the outside" (Hartoonian 2006, 272). Semper thus views the use of hanging carpets as the element that creates a sense of space and produces the boundaries of a room, rather than the walls with load-bearing functions (Mallgrave quoted in Hartoonian 2006, 288). It was this ability of textiles to provide a sense of being in a place, a sense of the interior, that led Semper ([1860] 2004, 247) to observe that the "beginning of building coincides with the beginning of textiles". Recently, film and media scholar Giuliana Bruno's influential notion of the "screen-membrane" similarly emphasizes such an affective sense of space while placing greater importance on the mediatic quality of textiles, linking architecture, fine art, moving image and fashion. This "screen", however, remains as a metaphorical fabric of the visual in the virtual age (Bruno 2014, 2-6). Building on Bruno's significant work, this essay explores "fabrics of the tactual", the type of spatiality generated through physical contact between everyday surfaces and our bodies and their movements. The English word "mark" shares its root with the Latin word margo ("margin") revealing an affinity with the notion of localization and territorialization. As the essential material of the living environment in which we eat, rest, create and love, cloth is the paradigm of surfaces and places engendered through living as marking. These marks are indexical traces which "guarantee" their privileged relation to the real and to materiality (Krauss 1977, 70; Doane 2007, 132). By "blind compulsion" (Peirce quoted in Doane 2007, 133), these marks evidence the present or past contiguity of bodies or the affinity (from the Latin affinitas, "bordering-on") between different "affectants". Textiles harbor visible or invisible touches with tactful blindness towards human-nonhuman distinctions, making possible a potentially uninterrupted link between space-textile-garment-skin. Understood as a matrix of indexical traces, these lived surfaces in the everyday environment can be brought together under the category of the "textile-sphere". The neologism underscores the ability of textiles to draw attention to the boundaries between self and other, between animate and inanimate, at the same time subverting these boundaries via its mimetic and palimpsestic qualities.

To inhabit, like the habit, is "under the guidance of tactile appropriation" (Taussig 1991, 149); we dwell and linger, leaving physical traces. Occurring in the act of inhabiting a place, therefore, is "a blurring of the boundaries between one's body and its proximal environment" (Ratcliffe 2018), to which our relation is inherently 
"interfacial"; that is to say, the act of inhabiting and the inhabited place are mutually generative. Henri Lefebvre considers such generation of space as "archi-textures": those spaces engendered by the traces of activities developed over time. Lefebvre (1991, 115118) emphasizes the indexical link between the inhabitant and the habitat by comparing "archi-textures" to a spider's web. The spider-silk is exuded from the body of the spider, whose movement lays down the web. In contrast to the more abstract metaphor of the "network", the lines of the spider's web are at once material presence and bodily trace, an extension of the spider's very being as it trails into the environment (Ingold 2008, 210-211). ${ }^{8}$ This sort of territory — one made to appear by the activities of its inhabitants - has long been recognized in architectural history. For example, for the ancient Greeks "the space of architecture was the space of ritual" (Pérez-Gómez 1985, 52). People periodically gathering and performing for a collective ritual such as gymnopaidiai created an "invisible wall", the sense of social space in which people do things together (McEwen 1993, 74). It was for this reason the Greek word chöros (a place) emerged from choros (dance), and the pre-Socratic idea of chōra is an uncertain space that can be continuously remade, as it is being woven by the movement of its inhabitants (McEwen 1993, 81, 83).

I suggest that such contingent spaces may be most effectively embodied in textiles, given the ability of cloth to create flexible architectural configurations and indexical and affective materiality. If medieval tapestries were prized and cherished as "movable atmosphere", instantly reproducing the ambience, insulation and acoustics of luxurious aristocratic residences even in battlefields, the temporary homes that textiles can create in contemporary military or refugee camps are ephemeral yet highly charged places, embodying the fragility of home while revealing the deep psychological and utilitarian human need to dwell and inhabit. An artistic example of affective space generated by human-nonhuman relationship is the Fluxus artist Joseph Beuys' Plight (1985): its spaces padded with thick rolls of felt maximized the insulating qualities of cloth. ${ }^{9}$ Within the installation, a sense of being protected from outside noise or temperature is accompanied by the sound of one's own breathing, blood circulation or racing pulse, overwhelmingly amplified by the heightened auditory sense, linking human body, textile and space in ways beyond the tangible or visible realm. It is impossible to separate between corporeality, materiality and sociality in Beuys' space, as affect transcends the human, generating relations amid nonhuman matter, place and ephemeral phenomena (Vannini 2015, 5-6). 
To explore the affective quality of textiles and their ability to generate a sense of place might then involve approaching spatial construction, not in terms of joining or layering but instead in terms of "swelling", perhaps like a breathing movement of inflating and deflating. To "swell" (schwellen) is precisely the word Walter Benjamin uses to contemplate "threshold experiences" in The Arcade Project (2002). Benjamin reminds us of the architectural sense of the word "threshold" (Schwelle) as a physical zone of transformation, passage or wave action, and therefore it should be carefully distinguished from the "boundary" (Benjamin 2002, 494). This conceptualization of experiential space — simultaneously temporal, material, bodily and psychological — is useful in recognizing the emergent and contingent spaces within everyday transitions. Cloth is the archetypal material of Schwelle, the threshold of everyday contacts. Worn cloth we wear reminds us of the permeable zone between the self and the world, which may appear when we stain, clean, caress or wrap things, as when we touch, "an infinity of others - other beings, other spaces, other times - are aroused" (Barad 2012, 206). This dynamic new dimension, a sort of processual formation and deformation of spatiality, moves elastically through intervals or the subtle relations between affectants. The critical methods of exploring the textile-sphere should then be in keeping with swelling or stretching movements.

\section{The skin, textiles, space and loss: Two critical perspectives}

In this section, two specific critical perspectives through which to further engage the spatiality of textiles are introduced: Didier Anzieu's (1989) psychoanalytic notion of the "skin ego" offers one perspective, Peter Sloterdijk's $(2011 ; 2016)$ philosophy of spheres ("spherology") another. Although both are human-centred approaches, they are useful in exploring an intimate spatiality which must always be created, rather than something pre-existing for us to enter. The spatiality engendered by accumulated markings, for humans, may first be experienced in the primary relationship between a baby and its mothering environment, especially in the sensorial experience of the skin, as I will go on to explain further below, borrowing Anzieu's theory. Recent studies tend to accentuate the skin not only as biological membrane but also as the affective interface that mediates social relations, including nonhuman objects. The biological skin is itself a complex substance, "both living and dead, a self-repairing, self-replacing material" which "lacks definitive boundaries, flowing continuously from the exposed surface of 
the body to its internal cavities" (Lupton 2002, 29). The skin is, both physically and socially, the threshold that mediates our contact with the world, often standing metonymically for the person as a whole (Benthien 2002, 18). Anthropologist Tim Ingold interprets the word "complexion" to illuminate the social, biological and psychological aspects of the human, inextricably linked in the skin. Used nowadays mainly in reference to facial skin, "complexion" reveals the impossibility of separating expression from affect, health, mood or the atmospherics of weather (Ingold 2017, 104). Complexion is the kind of surface that emerges in the very fusion of interior and exterior (Ingold 2017, 105) and it is in such relations of interfaciality, Ingold points out, that social life is lived.

Such understanding of the skin as a social and biological interface is effectively conceptualized in the idea of the Skin Ego. As in other object relations theories of psychoanalysis, with the Skin Ego (1989), Anzieu places great importance on the skin and sensorial contact in establishing a sense of self, and its continuous changes through material and social contact. The Skin Ego is a mental and spatial representation of the body which humans build, based on the experience of the skin. The sense of touch is of primary importance, but other senses are intrinsically linked to the sense of touch, as the skin here is understood as an intersensorial organ. ${ }^{10}$ From the moment a newborn baby is first held by its mothering person, his/her handling, swaddling and bathing touch leave "marks" on the baby's body-psyche. The Skin Ego evolves as the baby accumulates these marks made by its mothering environment. Humans are thus "indelibly inscribed with the imprint of the mother" (Lemma 2010, 2) and with the imprint of an expanding range of social contacts including nonhuman "objects" such as cloth, warmth, vibration or smell. ${ }^{11}$ The process of growing up involves a gradual separation from the mother to have a separate Skin Ego. This separation implies that we are all also marked by the process of loss or demarcation. Loss is inherent in the formation of the self. The increasing role that material culture-and textiles in particular-plays in a growing infant's life may function as the substitute of the mothering touch (Lee 2016, 17-19). The Skin Ego, therefore, emphasizes the palimpsestic aspect of the self-in-process through human and nonhuman contacts, and how the human and its physical environment are co-constitutive. The sense of the self emerges through the iterations of merging and demarcation, and this "becoming" cannot be separated from the sense of self within a space. Moreover, in a culture where it is commonplace to describe architecture as a purely visual art (Guy 2007, 248), the notion 
of the Skin Ego is a potentially useful framework for understanding architecture as a sensorial, material and affective space.

The importance of the link between the baby and its mothering environment is also emphasized in the philosophy of space which Peter Sloterdijk (1998-2004) developed in his Spheres trilogy. According to Sloterdijk (2005, 229), spheres are generated as they are animated by their inhabitants, and humans are an effect of the space they create (Sloterdijk 2009, 1) — not in that order, but in a strange loop. For both Anzieu and Sloterdijk, spatiality and existence are inseparable, as "the house of Being [is not] a simple cubicle that existing beings enter into and exit out of" (Sloterdijk 2012, 37-38). ${ }^{12}$ Sloterdijk's "microspherology" in Bubbles: Spheres I (2011) is about "the profound relationship from which we are born"; that is, the space created by the "reciprocal possession" within primary relationships (Sloterdijk 2005, 223-224). This primary dyadic relationship is operative in all later architectural activities, and therefore, humans cannot create an absolutely neutral space (Sloterdijk 2009, 2-3). This can be interpreted in such a way that any intimate spatiality is marked by the "reciprocal possession". Marking and being marked, then, are the conditions for existing through becoming, which might explain the human compulsion to mark the skin, cloth, walls, writing paper and other everyday surfaces, archi-textualizing the self. To Sloterdijk's (2009, 2-3) question, "[w]hat interiors will living beings wish to have if they bear within them the marks of being born?", textiles might provide an important answer, as they index the mutual possession between the marker and the marked. In "plural spherology" that he formulates in Foams: Spheres III (2016), this microsphere ("bubble") is the basis of contemporary social spatiality, in which an aggregation ("foams") of mutually constitutive yet mutually impermeable "bubbles" co-exist.

The two notions, considered together, hopefully explicate this new dimensionality that is the textilesphere, experienced as a continuum between surface, space and time. The textile-sphere is a relational and processual space with palimpsestic qualities, like the Skin Ego or "bubbles". Such flexible spatiality implicates immanent loss, in that the act of marking at once creates and divides social relations. This dual function of marking is at work in territorial or apotropaic marks on various living environments such as tattoos (Gell 1993); ancient or contemporary graffiti; carved or scorched marks on beams or pillars of vernacular architecture (Dean and Hill 2014; Easton 1999; Meeson 2005) or ritual deposits in the form of worn, fragmentary, damaged garments spatially distributed within a building (Eastop 2006). The act of 
marking generates self and intimate relational space, while at the same time triggering the loss or exclusion of what is not self, what is outside. The flexibility of the textilesphere means, however, that no inside-outside distinction is permanent, hence the difference between "threshold" and "boundary" (Benjamin 2002, 494).

\section{Home, carried through: Artistic interventions}

If the act of marking and the resulting marks constitute intimate social spheres, this is also an essential step in the artistic process. In this final section, a few examples of artistic intervention are contextualized with regard to the spatiality of textiles and the notion of home. Latent in the physical qualities of textiles is their ability to invoke nonphysical qualities such as empathy, atmosphere or the feeling of care, suggesting that home is both a physical and virtual space. The works maximize the ability of the textile to convey loss through its presence. They are mostly non-representational, drawing attention to the process of co-constitution between the maker(s) and materials through touch and movement. Making here is the process of marking. To paraphrase psychoanalyst Serge Tisseron (1994), seemingly useless acts of doodling — darkening letters, repetitive graphic patterns, scribblings - may be a way of investing the drawing or writing surface as a lived skin. These acts can be seen as a process of soliciting the surface to relate to the maker or writer (Tisseron 1994, 41). The familiar anxiety facing the blank surface before writing or drawing may arise from the fact that a contact has not taken place, thus neither the work nor the creator yet to exists. We build affinities with our material surroundings by marking them, just like a baby does with its mother who touches, holds and handles it. It is through such understanding of marking that everyday practice and artistic practice can be linked. This aspect may also be one of the reasons why artists choose cloth or cloth-like materials as their main medium. If immaculate glass screens or facades reflect an ocular-centric attitude and are a metaphor of the deterritorialization and decorporation of modern life (Virilio 1998, 181), then cloth perhaps is the material that simulates the intersensoriality of the Skin Ego most comprehensively. The material meaning of textiles is founded on "indexical traces of the touch, handling and holding that are the presence of an absence of the body" (Pajaczkowska 2010, 134). As the index produces "spatial immediacy and temporal anteriority", textiles are often used in an artistic context to evoke "an illogical conjunction between the here-now and the there-then" (Barthes 1977, 44). Combined 
with human touches and traces, textiles possess an almost frightening ability to stand in for an absent person within the context of an artistic work.

The works below draw attention to various skins and surfaces close to the human body, estranging the "naturalized" becoming of the human as a palimpsest of material and social contacts. For instance, American sculptor Robert Overby's rubbings - three-dimensional frottage — of vernacular buildings index lived spaces marked by the dwellers' bodies. His Madonna Door (5 October 1970)—with its wrinkles, folds and a pregnant swelling in its center-seems to merge architecture and the human body into a single organism (Yau 2018, 39). In his Barclay House series (4 August 1971), Overby cast the charred walls, doors, broken windows and furniture of a burned-out building, intensifying the quality of the index as the "ghostly traces of departed objects" (Krauss 1977, 75). It is as if visiting a deceased person's house and feeling that "his living frame had been caged by these walls, his breath had mingled with that atmosphere, his step had been on those stones" (Shelley 2000, 282). The series may look strangely familiar to contemporary viewers who are used to seeing wrecked and abandoned buildings in the wake of a disaster, in daily national and international news reports.

The sense of loss is also palpable in Heidi Bucher's gestural engagement with architecture and everyday objects (Munder 2015, 55) (Figure 1). Her Häutungen ("skinnings") or Raumhäute ("room skins") are imprints taken by pressing thin cloth against the surface of objects or interior spaces, smoothing liquid latex into the cloth, and then peeling it off just before it hardens. The inorganic skin changes its color as it dries, gradually degrading and becoming brittle, not unlike the skin of living organisms. Just as the in-between quality of latex let Eva Hesse and Louise Bourgeois explore the boundaries between bodies and their surroundings (Sherlock 2014), in Bucher's "room skins", latex seems to perform a space "formatted by the inhabitants" (Sloterdijk 2005, 232). The skinnings - as physical duplication cast by embalming, exfoliating and sloughing - bear the lived marks of the interior, documenting architecture both as palimpsest and improvised space. In the documentary film by Michael Koechlin (1990), which shows the process of making Kleines Glasportal, Bellevue Kreuzlingen (1988), Bucher appears to be merging with her surroundings, folding herself under the skin of the wall (Yau 2018, 37). As the latex skin takes flakes of paint, dust, the imprint of splinters, cracks, or nails with it (Cumming 2018), it also seems to take something immaterial with it. This sensation intensifies in her works which deal with the absent 
presence of bodies through the bedlinen they slept in, the underwear, shirts, petticoats, or aprons they wore every day. For instance, Anna Mannheimer with Target (1975), Otto-to-to-to-to-to (1975), Sally's Apron (1974) and La Mamma (1977) are items of clothing embalmed with latex and iridescent mother-of-pearl pigment. Resembling the skin of dragonflies or a snake's cyclical skin sheddings, these rubbings are traces of traces (Spence 2018), a swelling space-time like Benjamin's Schwelle, in which the body, skin, enveloping, belonging, time, and memory are all interchangeable (Ardalan 2018, 11, 13) (Figure 2).

The sense of home touched on by Bucher's skinnings is complex and ambivalent: home here is an object of celebration (of her childhood memories, her artistic studio, celebrated figures such as Sigmund Freud or Aby Warburg) as well as something to be laboriously exorcized (the patriarchal or institutional values to which she was exposed during her bourgeois upbringing). On the other hand, for the Columbian sculptor Doris Salcedo, a home is a thoroughly uninhabitable space, of which the memories are blocked. This sense of uninhabitable space is invocated with references to textiles (Basualdo and Salcedo 2000, 12). The acute sense of displacement is tangible in Salcedo's work through materials and objects familiar to our body, such as cloth, hair and domestic furniture. In Untitled (1998), a wooden chest of drawers with glass doors is choking on concrete. Akin to prostheses, metal rods and plates support the crushing weight of the concrete body, in which crumpled shirts are pressed against the panes "like bodies piling up behind windows" (Princenthal 2000, 72, 77) (Figure 3). The sheer "here-ness" of this textile-furniture-body hybrid seems to index absencesthe loss of homes, bodies and memories - or, rather, "absences are created by the marks and traces" (Basualdo and Salcedo 2000, 17). As Paul Celan translated the horror of the Holocaust through the disintegration of language and its structures (Basualdo and Salcedo 2000, 25), Salcedo effectively deploys cloth to make the loss present. As everyday materials, textiles bespeak the presence of a human being or become like "creatures" themselves (Basualdo and Salcedo 2000, 32). In Unland: the Orphan's Tunic (1997), old kitchen tables are made strange with "hundreds of tiny follicles laboriously bored" into the wooden skin with human hair threaded through them (Princenthal 2000, 82), while a tunic in thin fraying silk grows into the tables like a fragile skin (Huyssen 2000, 92) (Figure 4). The work alludes to the real-life experience of a six-year-old girl, who had witnessed her mother's killing: she had since worn the same tunic made by her mother day after day (Huyssen 2000, 96). The title Unland, 
then, is a place of unhabitable memory. While the sutures on and through the table attend the wound inflicted on its body and on those who suffered trauma, to those who did not experience the trauma first-hand, to be in the presence of the artwork is "to be wounded by their wounds" (Silverman 1996, 189). This transfer of wounds is effective as the works are non-representational. The painstaking handwork involves extended contact between the affectants - materials, objects, and makers - potentially creating a space of collective mourning. In Salcedo's work, the link between cloth, skin, and furniture is central for the material transposition of temporal experience into the space of work, thereby exorcizing the lost home and then making a new home, through which bodies and memories can exist again.

The relation of the human to its surroundings becomes explicit in Do Ho Suh's exquisitely rendered "fabric architecture," which looks light enough to be packed in a suitcase (Belcove 2017) (Figure 5). While inheriting Overby's and Bucher's technique of frottage, Suh's full-scale rubbings of architectural spaces are "drawn" in diaphanous rice paper, silk, or polyester. The effect is ghostly yet highly tactile. Architectural featuresthe grain of wood, the texture of walls, light switches, electrical outlets, doorknobs, sinks, bathtubs, and toilets - are spatially doubled by caressing every inch of the space with pastel-dipped fingertips. Entering the finished sculpture is "like stepping into a drawing" (Belcove 2017), highlighting the uncanny conflation between visual representation (drawing) and tactile duplication (molding). Suh's works seem to explore Virilio's $(1998,179)$ lament about contemporary spatiality, which often is "less defined by the materiality of architecture but rather by the ephemerality of the images with which we perceive the world". The tactual and affective materiality of cloth emphasizes the sculpture as a spatial palimpsest, a "worn" space. In Salcedo's work mentioned above, as well as in Ai Weiwei's installation at Konzerthaus (Berlin, 2016) (using salvaged life vests left by refugees who landed on the Greek Island of Lesbos), and in Tania Bruguera's performance at the Tate Modern (London, 2019), the material trace of the body on a markable surface is an artistic trope often deployed in dealing with the notion of home within the politics of migration and borders. Suh's work has also become particularly relevant in the wake of the recent migration crisis. His own experience of displacement — from Seoul to New York — was "less culture shock than architectural shock" (Rose 2017), having to get used to entirely different architectural features such as the height of the door or the door knob, revealing the extent to which human bodies are entwined in the fabric of the building, and how we become 
habitualized as we inhabit a space. Suh's fascination with the material links between the body and architecture is evident when he states that after living in his New York apartment for some time, it became a kind of skin; he even started to experience the space as "entering inside of him", as if it had shifted from a skin to an internal organ: "That's how your house gets inside of you" (Rose 2017).

As Suh was caressing the surface with his fingertips to apply pastel, his fingerprints started to wear off, giving up his own body to the architecture (Rose 2017) (Figure 6). His diaphanous fabric walls are then perhaps "a kind of graphic pruritus" as Barthes $(1985,162)$ contemplated Cy Twombly's surface as graffiti, a lived surface that is "dirtied, tainted, with an unclassifiable luminosity" (Barthes 1985, 167). The pastel hues are not simply visual, but a sort of tactile color of the skin, pointing to the interfaciality (Sloterdijk 2011; Ingold 2017) between the human and nonhuman. In The Book of Skin, Steven Connor uncovers the enigmatic link between the word "colour" and the intersensoriality of the skin (Anzieu 1989, 103. See Note 10):

The word "chromatic" derives from the Greek $\chi \rho \tilde{\omega} \mu \alpha$ (chroma), colour of the skin, complexion, style. $\chi \rho \tilde{\omega} \mu \alpha$ is related to $\chi \rho \omega ́ \varsigma$ (chros), skin, skin-colour, and to the verb $\chi \rho \omega ́ \zeta \varepsilon ı v$ (chroizien), to touch a surface or the skin ... Colour thus harbours the idea of something that both touches the skin, and is also itself, according to a curious logic of contagious replication, a kind of second skin, a layer, film or veil. The musical application of the metaphor in the chromatic scale perhaps draws out this idea. Where the diatonic scale is restricted to intervals of a full tone, the chromatic scale is coloured by the semitones that lie between these intervals, as it were, a fingertip or hair's-breadth away from the preceding or succeeding tone. The involvement of an idea of skin in the apprehension of colour is implied by words with tactile connotations. To say that something or somebody has a certain "cast" is to imply a dash or shading of colour, which may perhaps lean on the subsidiary meaning of "cast" as something shed or thrown off, and specifically a shed skin, as of a snake, spider or caterpillar. (Connor 2004, 151).

It is as if contact with the skin triggers a space to swell up from the touched surface, gradually perfuming and coloring the surrounding air. Perhaps a sort of "local fluid" or "particular disturbance of surfaces" that indexes the movements of the affects (DidiHuberman 2003, 280). The "semitones that lie between intervals", for Gernot Böhme $(2000,16)$, would create an "expanded corporeal space"; that is, something like the 
atmosphere. Just as when we are listening, we are outside ourselves (Böhme 2000, 18), being in a microsphere entails the ecstasy — from the Greek ekstasis, "being outside oneself"- of being outside of oneself (Sloterdijk 2005: 231-232). Suh's pastel-colored textile architecture - having taken bits of his fingertips and bits of his house- shows how the human and the nonhuman can "tincture" the environment through their ecstasies (Böhme 1993, 121-122). It is perhaps this type of chromatic atmosphere, the affective connection between dweller and dwelling, that constitutes a home which is "both real space and represented space" (Kim 2014, 30). At once indexical and iconic, Suh's tactile architectural drawings document the space of the everyday, turning his fingerprints into a translucent membrane, conflating the marker and the marked, surface, space, and atmosphere.

\section{Textile thinking beyond surface: swelling and stretching movement}

As the examples of artistic interventions above illustrate, textiles are the paradigm of material presence that holds the marks of human inhabitation. The relationships that cloth has with time, wear, and death brings us into contact with our own ephemerality and with the extent to which we and the material grow into each other. On the other hand, highly advanced textiles - smart textiles; intelligent textiles for sensorized built environments that responds to human voice, movement, or temperature; virtual textiles - have started to permeate through everyday lives. When geographer Nigel Thrift $(2005,233-234)$ pointed out in 2005 that screens have become "a vast geographical web of perception, a vast epistemic apparatus, and a new form of inhabitation", screens were mostly made of glass, only to be looked at. Now, in 2019, touch-enabled screens are increasingly merging with textiles and even with the skin, while the dematerialization of modern life transmutes our bodies and lives into images on screens, dressed in virtual textiles. This convoluted condition will affect how we come to think of our own bodies and relate to those of others. With such complex material, cultural, and social conditions as the backdrop, this essay suggests a new way of thinking about textiles of the most ordinary kind. As the application of advanced textiles widens, it is necessary that we re-evaluate the existing qualities that are taken for granted yet essential for our social and emotional lives. Textiles, even in their rudimentary form, still protect us as a mediating environment in the most challenging situations in which we must survive with very little. As one of the first experiences in 
this world, along with the mother's touch, cloth is like atmosphere, in that we are always already immersed in something almost imperceptible and yet very real (Sloterdijk 2005, 225). In this sense, "air has been made explicit' (Latour 2006, 104) by the textile-sphere, through which we come to see the absolute centrality of textiles in our lives, be they highly advanced or the most basic. Appraised from a position of contemporary spatial and perceptual awareness, and taking the importance of textiles in technologized built environments into consideration, textile thinking must now transcend humannonhuman, 2D-3D and material-immaterial dichotomies, and focus, instead, on the threshold in-between.

\section{Notes:}

1 In this article, the word "material" refers to things with physical properties including concrete stuff such as cloth, wood, table, etc. as well as less concrete stuff like air, smell, sound, etc. The word "immaterial" refers to non-physical phenomenon such as mood, atmosphere or feeling. This essay aims to show that the material-immaterial distinction is not as clear as is often assumed.

2 According to The Penguin Dictionary of Sociology (Abercrombie, Hill, and Turner 2006, 307) "primary relationship" is: "interpersonal relations characterized by emotional intensity, total commitment and mutual satisfaction. In a primary relationship, the total person is involved in the interaction. By contrast, secondary relationships are partial and ephemeral." In this essay, it mainly refers to relationships between a baby and his/her mothering person(s), between a couple, or between family members.

${ }^{3}$ In the gaming world, the word "skins" refers to outfits and accessories for virtual characters and "skinning" means dressing the virtual body or object by mapping textures onto surfaces. This digital clothing has now moved to the world of social media, in which people publish photos of themselves "wearing" a digitally rendered "outfit of the day". This is being adopted in sampling processes, look-books, and virtual catwalk collections in the fashion industry (Lieber 2019).

${ }^{4}$ Küchler $(2014,5)$ suggests that the heightened state of mobility in Polynesia (inter-island migration as a way of life), Polynesian's relational thinking, and the modular construction observed in their patchwork, lace, crocheting and contemporary artworks may be mutually generative.

${ }^{5}$ Scholars typically associated with relational approaches are John Dewey, William James, Gabriel Tarde, Alfred North Whitehead, Marilyn Strathern, Gilbert Simondon, Gilles 
Deleuze, Felix Guattari, Michel Serres, Bruno Latour, Tim Ingold, Michael Taussig, Elizabeth Grosz, Donna Haraway, Brian Massumi, Isabelle Stengers, Nigel Thrift, Jane Bennett, and Kathleen Stewart.

${ }^{6}$ The constituents of a system are variously theorized as "actants" or "actors" (Latour 2005), "transactants" (Dépelteau 2015), and "interactants" (Burkitt 2016).

7 In relational sociology, there exists no consensus as to whether the nonhuman should be considered as an actant or not. For instance, Nick Crossley $(2018,482)$ argues: "Given that sociology is the study of human societies ... I do not conceptalise such non-human objects as actors, in the manner of actor-network theory. Rather, I view them as resources, tools, obstacles and/or environments which mediate inter-human interactions and relations. Certain animals may constitute liminal cases, if and where they interact in meaningful ways with human actors."

${ }^{8}$ In "When ANT meets SPIDER", anthropologist Tim Ingold (2008) criticizes the approaches of Actor Network Theory (ANT), on the grounds that it does not take into account the different types of relations among different actors and processes, or the real material consequences of actions. Bruno Latour, who developed the theory from the position of science and technology studies (STS), acknowledges that ANT is "a bad tool for differentiating associations [because] it gives a black and white picture" (Latour quoted in Bosco 2006, 380)

${ }^{9}$ Plight was first installed at the Anthony d'Offay Gallery in London (1985). The exhibition I visited was a faithful reproduction of this original installation at Centre Georges Pompidou (Paris, 1994).

10 "The Skin Ego is a psychical surface which connects up sensations of various sorts and makes them stand out as forms against the original background formed by the tactile envelope: this is the Skin Ego's function of intersensoriality" (Anzieu 1989, 103. original emphasis).

${ }^{11}$ The function of "inscription": "The Skin Ego is the original parchment which preserves, like a palimpsest, the erased, scratched-out, written-over, first outlines of an 'original' pre-verbal writing made up of traces upon the skin." (Anzieu 1989, 105)

${ }^{12}$ In Heidegger's latent spatial philosophy in Being and Time, which Peter Sloterdijk (2012, 3738 ) traces, Da-sein is suggested to have an essentially relational character: "Because Dasein is always already a completed act of inhabiting, spatiality and existence are inseparable. ... the house of Being [is not] a simple cubicle that existing beings enter into and exit out of. Its structure is more akin to a globe of care in which Da-sein has spread in its ex-stasis." 


\section{References:}

Abercrombie, Nicholas, Stephen Hill and Bryan S. Turner. 2006. The Penguin Dictionary of Sociology, 5th edn. London: Penguin.

Anzieu, Didier. 1989. The Skin Ego, translated by Chris Turner, New Haven, CT; London: Yale University Press.

Ardalan, Ziba. 2018. "The Escapades of Anna Mannheimer from the House of Man and Other Stories." in Heidi Bucher, edited by Ziba Ardalan, 7-15. London: Parasol Unit.

Barad, Karen. 2012. "On Touching: The Inhuman that Therefore I Am." Differences: A Journal of Feminist Cultural Studies 23 (3): 206-223.

Barthes, Roland. 1977. "Rhetoric of the Image." in Image Music Text, translated by Stephen Heath, 32-51. London: Fontana Press.

Barthes, Roland. 1985. "Cy Twombly: Works on Paper." in The Responsibility of Forms: Critical Essays on Music, Art and Representation, translated by Richard Howard, 157-176. New York: Hill \& Wang.

Basualdo, Carlos and Doris Salcedo. 2000. "Interview." in Doris Salcedo, 6-35. London: Phaidon.

Belcove, Julie L. 2017. "Artist Do Ho Suh’s Houses of Memory." Financial Times, January 26. https://www.ft.com/content/a187c15e-e287-11e6-9645c9357a75844a.

Benjamin, Walter. 2002. The Arcades Project, Cambridge, MA; London: Harvard University Press.

Benthien, Claudia. 2002. Skin: On the Cultural Border between Self and the World, New York: Columbia University Press.

Böhme, Gernot. 1993. "Atmosphere as the Fundamental Concept of a New Aesthetics." Thesis Eleven 36: 113-126.

Böhme, Gernot. 2000. "Acoustic Atmospheres: A Contribution to the Study of Ecological Aesthetics." Soundscape: The Journal of Acoustic Ecology 1 (1): 1418.

Bosco, Fernando J. 2006. "Actor-Network Theory, networks, and relational approaches in human geography." in Approaches to Human Geography, edited by Stuart Aitken and Gill Valentine, 136-146. London; Thousand Oaks, CA; New Delhi: SAGE. 
Bruno, Giuliana. 2014. Surface: Matters of Aesthetics, Materiality, and Media. London; Chicago: University of Chicago Press.

Burkitt, Ian. 2016. "Relational Agency: Relational Sociology, Agency and Interaction." European Journal of Social Theory, 19 (3): 303-321.

Connor, Steven. 2004. The Book of Skin. London: Reaktion.

Crossley, Nick. 2018. "Networks, Interactions and Relations." in The Palgrave Handbook of Relational Sociology, edited by François Dépelteau, 481-498. London: Palgrave Macmillan.

Cumming, Laura. 2018. "Heidi Bucher Review: Memories are Made of This." The Guardian, September 23, https://www.theguardian.com/artanddesign/2018/sep/23/heidi-bucher-parasolunit-london-review.

Dean, John, and Nick Hill. 2014. "Burn Marks on Buildings: Accidental or Deliberate?" Vernacular Architecture 45 (1): 1-15.

Dépelteau, François. 2015. "Relational Sociology, Pragmatism, Transactions and Social Fields." International Review of Sociology 25 (1): 45-64.

Dépelteau, François. 2018. "Relational Thinking in Sociology: Relevance, Concurrence and Dissonance." in The Palgrave Handbook of Relational Sociology, edited by François Dépelteau, 3-34. London: Palgrave Macmillan.

Didi-Huberman, Georges. 2003. "The Imaginary Breeze: Remarks on the Air of the Quattrocento." Journal of Visual Culture 2 (3): 275-289.

DeLanda, Manuel. 2006. A New Philosophy of Society: Assemblage Theory and Social Complexity. London; New York: Continuum.

Deleuze, Gilles and Felix Guattari. 1987. A Thousand Plateaus. Minneapolis, MN: University of Minnesota Press.

Doane, Mary Ann. 2007. "The Indexical and the Concept of Medium Specificity." Differences: A Journal of Feminist Cultural Studies 18 (1): 128-152.

Easton, Timothy. 1999. "Ritual Marks on Historic Timber." Weald \& Downland Open Air Museum Newsletter, Spring: 22-28.

Eastop, Dinah. 2006. "Outside In: Making Sense of the Deliberate Concealment of Garments within Buildings." Textile: The Journal of Cloth and Culture 4 (3): $238-255$.

Gell, Alfred. 1993. Wrapping in Images: Tattooing in Polynesia. Oxford: Clarendon Press. 
Grusin, Richard. 2015. "Introduction." in The Nonhuman Turn, edited by Richard Grusin, vii-xxix. Minneapolis, MN; London: University of Minnesota Press. Guy, Simon. 2007. "Discipline and Disruption: Making Senses of the City." Senses \& Society 2 (2): 247-252.

Haraway, Donna. 1991. "A Cyborg Manifesto: Science, Technology, and SocialistFeminism in the Late Twentieth Century." in Simians, Cyborgs and Women: The Reinvention of Nature, 149-181. New York; Abingdon: Routledge.

Haraway, Donna. 2003. Companion Species Manifesto: Dogs, people, and significant otherness. Chicago: Prickly Paradigm Press.

Hartoonian, Gevork. 2006. "The Fabric of Fabrication." Textile: The Journal of Cloth and Culture 4 (3): 270-291.

Harris, Jane. 2013. Digital Skin. Textile: Cloth and Culture, 11 (3): 242-261.

Human Flow. 2017. [film] Directed by Ai Weiwei Germany: Participant Media.

Huyssen, Andreas. 2000. "Unland: The Orphan"s Tunic." in Doris Salcedo, 90-102. London: Phaidon.

Igoe, Elaine. forthcoming in 2020. "Where Surface Meets Depth." in Surface Apparition: Material Medium Affect, edited by Yeseung Lee. London; New York: Bloomsbury.

Ingold, Tim. 2008. "When ANT Meets SPIDER: Social Theory for Arthropods." In Material Agency: Towards a Non-Anthropocentric Approach, edited by Carl Knappett and Lambros Malafouris, 209-215. New York: Springer.

Ingold, Tim. 2017. "Surface Visions." Theory, Culture \& Society 34 (7-8): 99-108.

Joy, Eileen A. and Craig Dionne. 2010. "Before the Trains of Thought Have Been Laid down so Firmly: The Premodern Post/Human." Postmedieval: A Journal of Medieval Cultural Studies, 1 (1-2): 1-9.

Kim, Clara. 2014. "Rubbing is Loving: Do Ho Suh"s Archeology of Memory." in Do Ho Suh Drawings, edited by Rochelle Steiner, 27-32. Munich; London; New York: DelMonico Books; Prestel.

Krauss, Rosalind. 1977. "Notes on the Index: Seventies Art in America." October 3: 68-81.

Küchler, Susanne. 2008. "Technological Materiality: Beyond the Dualist Paradigm." Theory, Culture \& Society, 25 (1): 101-120.

Küchler, Susanne. 2014. "Additive Technology and Material Cognition: A View from Anthropology." Journal of Cognition and Culture 14 (5): 385-399. 
Latour, Bruno. 2005. Reassembling the Social: An Introduction to Actor-NetworkTheory. Oxford; New York: Oxford University Press.

Latour, Bruno. 2006. "Air." in Sensorium: Embodied Experience, Technology and Contemporary Art, edited by Caroline A. Jones, 104-107. Cambridge, MA: MIT Press.

Lee, Yeseung. 2016. Seamlessness: Making and (Un)Knowing in Fashion Practice. Bristol; Chicago: Intellect.

Lefebvre, Henri. [1974] 1991. The Production of Space, translated by Donald Nicholson-Smith. Oxford; Cambridge, MA: Blackwell.

Lieber, Chavie. (2019) "Would You Buy a Virtual Pair of Nikes?" The Business of Fashion, July 8. https://www.businessoffashion.com/articles/fashiontech/virtual-fashion-digital-products.

Lupton, Ellen. 2002. Skin: Surface, substance, and design. New York: Princeton Architectural Press.

Massumi, Brian. 1995. "The Autonomy of Affect." Cultural Critique 31: 83-109.

McEwen, Indra Kagis. 1993. Socrates' Ancestor: An Essay on Architectural Beginnings. Cambridge, MA: London: MIT Press.

Meeson, Bob. 2005. "Ritual Marks and Graffiti: Curiosities or Meaningful Symbols?" Vernacular Architecture 36 (1): 41-48.

Munder, Heike. 2015. "The Act of Shedding the Skin." in Heidi Bucher, edited by Karen Marta and Simon Castets, 55-60. New York: Swiss Institute.

Pajaczkowska, Claire. 2010. "Tension, Time and Tenderness: Indexical Traces of Touch in Textiles." in Digital and Other Virtualities. New Encounters: Arts, Cultures, Concepts, edited by Antony Bryant and Griselda Pollock, 134-148. London; New York: I.B.Tauris.

Pérez-Gómez, Alberto. 1985. "The Myth of Daedalus." AA Files 10: 49-52.

Princenthal, Nancy. 2000. "Silence Seen." in Doris Salcedo, 38-88. London: Phaidon. Ratcliffe, Matthew. 2018. "Perception, Exploration, and the Primacy of Touch." in The Oxford Handbook of 4E Cognition, edited by Albert Newen, Leon De Bruin and Shaun Gallagher [ebook]. Oxford: Oxford University Press.

Rose, Julian. 2017. "Do Ho Suh." Artforum International, January 19, https://www.artforum.com/interviews/-66014.

Semper, Gottfried. [1860] 2004. Style in the Technical and Tectonic Arts, Or, Practical Aesthetics. Santa Monica: CA: The Getty Centre. 
Shelley, Mary. [1824] 2000. "On Ghosts." in Gothic Documents: A Sourcebook 17001820, edited by Emma J. Clery and Robert Miles, 280-285. Manchester; New York: Manchester University Press.

Sherlock, Amy. 2014. "Heidi Bucher." Frieze, https://frieze.com/article/heidi-bucher [accessed: 21/12/2018].

Silverman, Kaja. 2013. The Threshold of the Visible World. London; New York: Routledge.

Sloterdijk, Peter. 2005. "Foreword to the theory of spheres." in Cosmograms, edited by Melik Obanian and Jean-Christophe Royaux, 223-240. New York: Lukas and Sternberg.

Sloterdijk, Peter. 2009. "Spheres Theory: Talking to Myself about the Poetics of Space. A Lecture given at Harvard University Graduate School of Design. 17 February." Harvard Design Magazine 30: 1-8.

Sloterdijk, Peter. 2011. Bubbles: Spheres I (Microspherology), translated by Wieland Hoban. Los Angeles: Semiotext.

Sloterdijk, Peter. 2012. "Nearness and Da-sein: The Spatiality of Being and Time." translated by Peer Illner, Theory, Culture \& Society, 29 (4-5): 36-42.

Sloterdijk, Peter. 2016. Foams: Spheres III (Plural Spherology), translated by Wieland Hoban. Los Angeles: Semiotext.

Smith, Elizabeth A. T. 2014. "Architecture and the Drawings of Do Ho Suh." in Do Ho Suh Drawings, edited by Rochelle Steiner, 19-25. Munich; London; New York: DelMonico Books; Prestel.

Spence, Rachel. 2018. "Do Ho Suh in Venice: The Lives of Others." Financial Times, 11 May. https://www.ft.com/content/e7cc1056-51e5-11e8-84f4-43d65af59d43. Taussig, Michael. 1991. "Tactility and Distraction." Cultural Anthropology 6 (2): 147153.

Thrift, Nigel. 2005. "Beyond Mediation: Three New Material Registers and Their Consequences." in Materiality, edited by Daniel Miller, 231-256. Durham, NC; London: Duke University Press.

Thrift, Nigel. 2010. "Understanding the Material Practices of Glamour." in The Affect Theory Reader, edited by Melissa Gregg and Gregory Seigworth, 289-308. Durham, NC; London: Duke University Press.

Tisseron, Serge. 1994. "All Writing is Drawing: The Spatial Development of the Manuscript." Yale French Studies 84: 29-42. 
Vannini, Phillip. 2015. "Non-Representational Research Methodologies: An Introduction." in Non-Representational Methodologies: Re-Envisioning Research, edited by Phillip Vannini, 1-18. London; New York: Routledge.

Virilio, Paul. 1998. "Architecture in the Age of Its Virtual Disappearance: An Interview with Paul Virilio." in The Virtual Dimension, edited by John Beckman, 178187. New York: Princeton Architectural Press.

Yau, John. 2018. "If These Walls Could Talk." in Heidi Bucher, edited by Ziba Ardalan, 37-41. London: Parasol Unit.

\section{Figures:}

Figure 1. Ablösen der Haut I-Herrenzimmer, c. 1979. Heidi Bucher. Photo by Hans Peter Siffert. (C) The Estate of Heidi Bucher

Figure 2. Anna Mannheimer with target, c. 1975. Heidi Bucher. Textile, Latex, Motherof-pearl pigments. $213 \times 200 \mathrm{~cm}$. Photo by Hans Peter Siffert. (C) The Estate of Heidi Bucher

Figure 3. Untitled (detail), c. 1998. Wooden cabinet with glass, concrete, steel, and clothing (183.5 x $99.5 \times 33 \mathrm{~cm})$. Collection of Lisa and John Miller, fractional and promised gift to the San Francisco Museum of Modern Art (SFMOMA). (C) Doris Salcedo. Photo credit: David Heald, 2011. Courtesy of White Cube, London.

Figure 4. Unland: the orphan's tunic (detail), c. 1997. Wooden tables, silk, human hair, and thread $(80$ x 245 x $98 \mathrm{~cm})$. "La Caixa" Contemporary Art Collection. (C) Doris Salcedo. Photo credit: David Heald, 2011. Courtesy of White Cube, London.

Figure 5. 'Passage/s' (detail), c. 2016. Do Ho Suh. Photography: Thierry Bal. Courtesy the artist, Lehmann Maupin (New York; Hong Kong) and Victoria Miro (London; Venice). (C) Do Ho Suh

Figure 6. Do Ho Suh: "Rubbing / Loving" (production still the Extended Play film), Courtesy Art21, art21.org, founded 1997. (C) Art21, Inc. 2016. 